\title{
Dysphagia Caused by Ossificaion of the Cervical Anterior Longitudinal Ligament
}

\author{
Seok Won Kim¹, Hyun-Sook Kim² \\ Department of Neurosurgery, Chosun University Hospital ${ }^{1}$, Gwangju, \\ Department of Internal Medicine, Soonchunhyang University Seoul Hospital ${ }^{2}$, Seoul, Korea
}

\section{Case Report}

Patient: 57-years-old male

Chief complaint: Dysphagia, even to liquid, that has progressed for 5 months

Physical examination: Pain and motion limitation of neck

Past medical history: He did not have a specific history of diabetes, hypertension and trauma.

Radiologic findings: Simple lateral radiography showed ossification of the anterior longitudinal ligament (OALL) at the level of C3-C5 (Figure 1A). Computed tomography images re- vealed compression of oropharynx and esophagus caused by OALL (Figure 1B, arrows).

Clinical course: He underwent the removal of OALL by anterior approach. After surgery, the ossified mass was removed successfully and the distance between trachea and OALL was increased (Figure 1C, arrowheads). He recovered on full consistency diet 2 weeks after surgery.

\section{Discussion}

Osteophytes of cervical vertebrae including OALL are derived
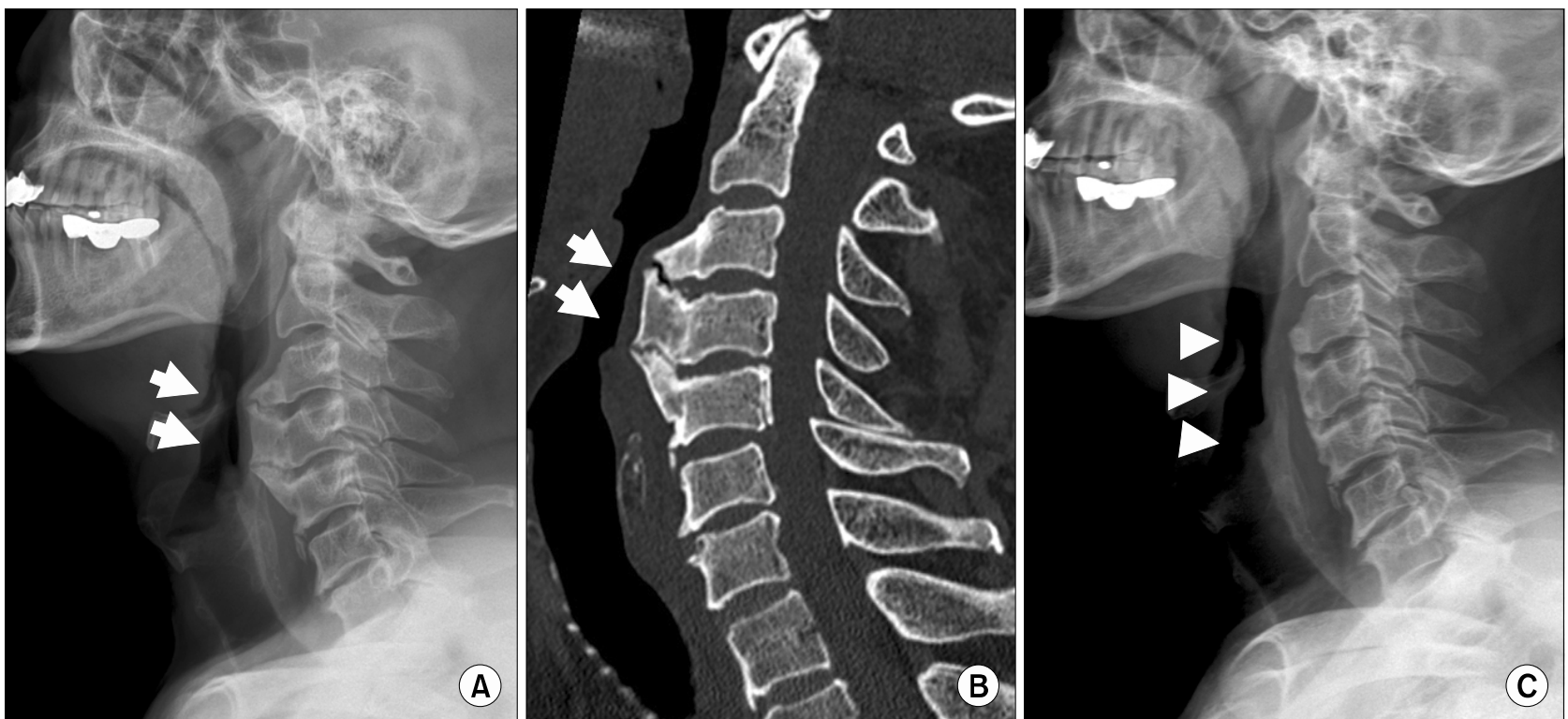

Figure 1. (A) It shows ossification of the anterior longitudinal ligament (OALL) from C3 to C5 (arrows). (B) Cervical computed tomography image shows compression of trachea by OALL (arrows). (C) Postoperative cervical radiograph shows removal of OALL which have compressed the esophagus and trachea (arrow heads).

<Received : April 24, 2013, Accepted : June 20, 2013>

Corresponding to : Hyun-Sook Kim, Division of Rheumatology, Department of Internal Medicine, The Soonchunhyang University Seoul Hospital, 59, Daesagwan-ro, Yongsan-gu, Seoul 140-743, Korea. E-mail : healthyra@schmc.ac.kr

pISSN: 2093-940X, eISSN: 2233-47 I8

Copyright (c) 2013 by The Korean College of Rheumatology

This is a Free Access article, which permits unrestricted non-commerical use, distribution, and reproduction in any medium, provided the original work is properly cited 
from degenerative changes usually remain clinically asymptomatic (1). Their incidences are common of the elderly population, but progression to dyspahgia is rare. Dysphagia resulted from cervical OALL, although uncommon, is an treatable cause of dysphagia that must be identified (2).

\section{References}

1. Lecerf P, Malard O. How to diagnose and treat symptomatic anterior cervical osteophytes? Eur Ann Otorhinolaryngol Head Neck Dis 2010;127:111-6.

2. Epstein NE, Hollingsworth R. Ossification of the cervical anteriorlongitudinal ligament contributing to dysphagia. Case report. J Neurosurg 1999;90(2 Suppl):261-3. 